\title{
Editorial \\ Gut Microbiota and Metabolism in Different Stages of Life and Health
}

\author{
Shanthi G. Parkar $1, *$ (D) and Pramod K. Gopal 2,3 (D) \\ 1 Seed Health Inc., Venice, Los Angeles, CA 90291, USA \\ 2 New Zealand Institute for Plant and Food Research, Palmerston North 4442, New Zealand; \\ pramod.gopal@plantandfood.co.nz \\ 3 Riddet Institute, Massey University, Palmerston North 4442, New Zealand \\ * Correspondence: shanthi@seed.com
}

check for

updates

Citation: Parkar, S.G.; Gopal, P.K. Gut Microbiota and Metabolism in Different Stages of Life and Health. Microorganisms 2022, 10, 474. https://doi.org/10.3390/ microorganisms10020474

Received: 10 February 2022 Accepted: 17 February 2022 Published: 21 February 2022

Publisher's Note: MDPI stays neutral with regard to jurisdictional claims in published maps and institutional affiliations.

Copyright: () 2022 by the authors Licensee MDPI, Basel, Switzerland. This article is an open access article distributed under the terms and conditions of the Creative Commons Attribution (CC BY) license (https:// creativecommons.org/licenses/by/ $4.0 /)$.
In a very fascinating read, John Goodsir, a Scottish surgeon, describes how he isolated "vegetable organisms" from the "ejected fluid" from the stomach of his 19-year-old patient. He named the organism Sarcina ventriculi and prescribed antibacterial creosote drops, resulting in the elimination of symptoms [1]. This was probably the first case where human gastrointestinal microbiota was associated with disease. Since then, many more causative links have been established between microorganisms and infectious diseases such as typhoid fever, tuberculosis, and plague [2-4]. The advent of omics technologies has accelerated our understanding of the role of the gut microbiota in human physiology. Microbes are now known to modulate vitamin biosynthesis [5], maturation of the gastrointestinal tract and the immune system [6], protection against pathogens [7], and the development of non-communicable diseases such as obesity, metabolic syndrome, asthma and cancer [8].

Natural history studies of the human gut microbiome present the new-born infant to harbor a sparse gut microbiome [6,9], which then evolves by about 3 years of age to a 3 to 10 trillion cell community $[6,10]$. Healthy development of the gut microbiome within the first 1000 days of life is believed to be important for protection against many diseases later in life [11,12]. A diet incorporating fiber-rich or fermented foods has been shown to modulate gut microbiota in humans, from infants to adults [11,13-15]. The fiber reaches the large intestine and serves as a source of carbon for the microbial community, which in turn generate metabolites, mainly short chain fatty acids (SCFAs) that nourish both the microbiota and the host $[7,16]$.

This Special Issue includes nine original articles and reviews that encompass the microbiome story at different stages of life and health. Three papers focus on the role of maternal microbiome or various foods on developing infant gut microbiome through weaning periods. In a review on the maternal microbiome, the authors examine how the mother's oral, gut, and vaginal microbiota changes throughout pregnancy in parallel with her hormonal levels [17]. The review examines maternal microbial dysbiosis mediated mechanisms contributing to gestational diabetes and preeclampsia in the mother, and fetal growth restriction, preterm/still birth, or infections in the infant. Once the infant is born, the food ideally recommended is the mother's milk, as it helps seed and feed up to $30 \%$ of the infant gut microbiota [18-20]. In a study based out of Indonesia, the authors followed the microbiome in 51 mother-infant dyads from birth to two years of age [21]. The dominant microbes in the mothers' milk were Staphylococcus and Streptococcus, while maternal feces were dominated by Prevotella 9 and members of the Clostridium cluster IV. Feces of 3-monthold infants were dominated by B. longum subsp. infantis and B. bifidum, that are well-known for their capacity to metabolize the oligosaccharides in breastmilk [22,23]. As the infant grows, it is recommended that a more complex diet, including plant-based foods, meat and dairy, complement the breastmilk to meet the infant's growth and development needs [11]. 
Thirty-two ingredients relevant for the formulation of infant-complementary foods were shown to differentially modulate the developing infant microbiome using an in vitro gut model [24]. The well-validated laboratory simulation of digestion and colonic fermentation employed in this study also offers an opportunity to examine how food blends can support age-specific or personalized changes in the developing infant microbiome $[25,26]$.

Three original studies in this Special Issue describe health-microbiome interactions in three disease states. The study by Esparbès and colleagues examined the subgingival microbiota and cytokines in adult volunteers with periodontitis [27]. This is the first study comparing these parameters in healthy and diseased sites in the oral cavity of the same individual. The diseased oral sites had higher relative abundances of Synergistetes and Spirochaetes, while the healthy sites were enriched in Actinobacteria. They also identified Desulfobulbus, Filifactor and TM7 as potential biomarkers of periodontitis, concurring with data reviewed by Patini and colleagues [28]. The second study is a pilot clinical trial examining microbial differences at the species level between morbidly obese and normal weight subjects [29]. Using a commercially available qPCR-based Precision Microbiome Profiling (PMP $\left.{ }^{\mathrm{TM}}\right)$ method they found significant changes in the relative abundance of 17 of the 104 species analyzed. Of note were the decreases in Akkermansia muciniphila, two Bifidobacterium species, many butyrate producers including Faecalibacterium prausnitzii and Ruminococcus bromii, and one methanogen Methanobacter smithii. Many of these microorganisms have shown significant inverse correlations with body mass index in previous studies [30-34]. The third study is the first of its kind to detail the microbiome changes in adults with phenylketonuria (PKU) [35]. The key finding of this study was that, compared to the control group, PKU positive gut microbiome was poorer in the clostridial members Faecalibacterium, an unknown Lachnospiraceae and Romboutsia, and richer in Enterocloster (also a Lachnospiraceae member). Further metagenomic studies will provide useful insights to evaluate dietary strategies for PKU patients.

The role of the gut microbiota in dietary fiber metabolism to SCFAs and the consequent physiological outcomes is well characterized $[7,11,16]$. Microbiota also breaks down other diet-derived molecules such as polyphenols to generate metabolites that have a prebiotic effect $[36,37]$. Kiwifruit is a source of fiber and polyphenols that have been shown to be accessed and metabolized by gut microbiota, using an in vitro model of gastrointestinal digestion and fermentation [38]. Parkar and colleagues used a similar in vitro approach again to demonstrate that the digested green and gold-fleshed kiwifruit are rich in precursors of dopamine and serotonin, respectively [39]. At the colonic fermentation stage, the green and gold-fleshed kiwifruit increased L-dihydroxyphenylanine (L-DOPA, the dopamine precursor) and $\gamma$-aminobutyric acid (GABA), respectively. The digesta and fermenta, when incubated with gut epithelial cells, modulated genes related to gut tight junction, inflammation, and circadian rhythm. This study indicates that kiwifruit is potentially a source of physiologically relevant biogenic amines that are associated with functions such as sleep [40]. Indeed, kiwifruit has been shown to potentiate sleep via pathways implication serotonin and GABA [41,42]. On a similar theme, another article reviews edible mushrooms as microbiome-modulating functional foods [43]. Mushrooms are rich sources of $\beta$-glucan polysaccharides that have a prebiotic effect. The authors also review herbal beverages and their polyphenols, which act both as antioxidants and as prebiotics. Both mushrooms and herbal teas are also a source of microRNAs (miRNAs) that can interact with gut bacteria.

Lastly, this Special Issue features a review of gut microbial pathways resisting colonization of the pathogen Clostridiodes difficile in the large intestine [44]. C. difficile infection (CDI) causes severe diarrhea and colitis, with significant morbidity and fatality rates. While antibiotics are used for CDI management, microbial pathways may potentiate colonization resistance against $C$. difficile. Microbial metabolites, such as secondary bile acids, SCFAs, antimicrobials, or competition for nutrients such as proline, that are required by the pathogen for proteolytic fermentation, offer directions to develop new therapeutics against this gut infection. 
Collectively, the original articles and reviews in this Special Issue present a blend of valuable data and insights adding to the growing body of knowledge in the field of diet-microbiome-host interactions.

Funding: This work received no external funding.

Acknowledgments: We would like to thank all authors who contributed their excellent papers to this Special Issue. We thank the reviewers for their valuable help in further improving all manuscripts to the highest standard of quality before being published.

Conflicts of Interest: The authors declare no conflict of interest.

\section{References}

1. Goodsir, J. Mr Goodsir's case of vegetable organisms ejected from the stomach. Edinb. Med. Surg. J. 1842, 57, 430-443. [PubMed]

2. Farré-Maduell, E.; Casals-Pascual, C. The origins of gut microbiome research in Europe: From Escherich to Nissle. Hum. Microbiome J. 2019, 14, 100065. [CrossRef]

3. Mohr, K.I. How to overcome the antibiotic crisis, facts, challenges, technologies and future perspectives. Curr. Top. Microbiol. Immunol. 2016, 237-272. [CrossRef]

4. Sahu, S.; Hayes, W. The human microbiome: History and future. J. Pharm. Pharm. Sci. 2020, 23, 406-411. [CrossRef]

5. Arumugam, M.; Raes, J.; Pelletier, E.; Le Paslier, D.; Yamada, T.; Mende, D.R.; Fernandes, G.R.; Tap, J.; Bruls, T.; Batto, J.M.; et al. Enterotypes of the human gut microbiome. Nature 2011, 473, 174-180. [CrossRef]

6. Tamburini, S.; Shen, N.; Wu, H.C.; Clemente, J.C. The microbiome in early life: Implications for health outcomes. Nat. Med. 2016, 22, 713-722. [CrossRef]

7. Louis, P.; Scott, K.P.; Duncan, S.H.; Flint, H.J. Understanding the effects of diet on bacterial metabolism in the large intestine. J. Appl. Microbiol. 2007, 102, 1197-1208. [CrossRef]

8. Blumberg, R.; Powrie, F. Microbiota, disease, and back to health: A metastable journey. Sci. Transl. Med. 2012, 4, 137rv137. [CrossRef]

9. Yassour, M.; Vatanen, T.; Siljander, H.; Hämäläinen, A.-M.; Härkönen, T.; Ryhänen, S.J.; Franzosa, E.A.; Vlamakis, H.; Huttenhower, C.; Gevers, D.; et al. Natural history of the infant gut microbiome and impact of antibiotic treatment on bacterial strain diversity and stability. Sci. Transl. Med. 2016, 8, 343ra381. [CrossRef]

10. Sender, R.; Fuchs, S.; Milo, R. Revised estimates for the number of human and bacteria cells in the body. PLoS Biol. 2016, 14, e1002533. [CrossRef]

11. Laursen, M.F.; Bahl, M.I.; Michaelsen, K.F.; Licht, T.R. First foods and gut microbes. Front. Microbiol. 2017, 8, 356. [CrossRef] [PubMed]

12. Milani, C.; Duranti, S.; Bottacini, F.; Casey, E.; Turroni, F.; Mahony, J.; Belzer, C.; Delgado Palacio, S.; Arboleya Montes, S.; Mancabelli, L.; et al. The first microbial colonizers of the human gut: Composition, activities, and health implications of the infant gut microbiota. Microbiol. Mol. Biol. Rev. 2017, 81, e00036-17. [CrossRef] [PubMed]

13. Koponen, K.K.; Salosensaari, A.; Ruuskanen, M.O.; Havulinna, A.S.; Männistö, S.; Jousilahti, P.; Palmu, J.; Salido, R.; Sanders, K.; Brennan, C.; et al. Associations of healthy food choices with gut microbiota profiles. Am. J. Clin. Nutr. 2021, 114, 605-616. [CrossRef] [PubMed]

14. Laursen, M.F. Gut Microbiota Development: Influence of Diet from Infancy to Toddlerhood. Ann. Nutr. Metab. 2021, 77, 21-34. [CrossRef] [PubMed]

15. Wastyk, H.C.; Fragiadakis, G.K.; Perelman, D.; Dahan, D.; Merrill, B.D.; Yu, F.B.; Topf, M.; Gonzalez, C.G.; Van Treuren, W.; Han, S.; et al. Gut-microbiota-targeted diets modulate human immune status. Cell 2021, 184, 4137-4153.e4114. [CrossRef]

16. Koh, A.; De Vadder, F.; Kovatcheva-Datchary, P.; Backhed, F. From dietary fiber to host physiology: Short-chain fatty acids as key bacterial metabolites. Cell 2016, 165, 1332-1345. [CrossRef]

17. Amir, M.; Brown, J.A.; Rager, S.L.; Sanidad, K.Z.; Ananthanarayanan, A.; Zeng, M.Y. Maternal microbiome and infections in pregnancy. Microorganisms 2020, 8, 1996. [CrossRef]

18. Singh, K.S.; Singh, B.P.; Rokana, N.; Singh, N.; Kaur, J.; Singh, A.; Panwar, H. Bio-therapeutics from human milk: Prospects and perspectives. J. Appl. Microbiol. 2021, 131, 2669-2687. [CrossRef]

19. Pannaraj, P.S.; Li, F.; Cerini, C.; Bender, J.M.; Yang, S.; Rollie, A.; Adisetiyo, H.; Zabih, S.; Lincez, P.J.; Bittinger, K.; et al. Association between breast milk bacterial communities and establishment and development of the infant gut microbiome. JAMA Pediatr. 2017, 171, 647-654. [CrossRef]

20. World Health Organization. WHOI The Optimal Duration of Exclusive Breastfeeding: Report of the Expert Consultation; World Health Organization: Geneva, Switzerland, 2001; Available online: https://apps.who.int/nutrition/publications/infantfeeding/WHO_ NHD_01.09/en/index.html (accessed on 11 January 2021).

21. Ding, M.; Yang, B.; Khine, W.W.T.; Lee, Y.-K.; Rahayu, E.S.; Ross, R.P.; Stanton, C.; Zhao, J.; Zhang, H.; Chen, W. The specieslevel composition of the fecal Bifidobacterium and Lactobacillus genera in indonesian children differs from that of their mothers. Microorganisms 2021, 9, 1995. [CrossRef] 
22. Asakuma, S.; Hatakeyama, E.; Urashima, T.; Yoshida, E.; Katayama, T.; Yamamoto, K. Physiology of consumption of human milk oligosaccharides by infant gut-associated bifidobacteria. J. Biol. Chem. 2011, 286, 34583-34592. [CrossRef] [PubMed]

23. Garrido, D.; Ruiz-Moyano, S.; Lemay, D.G.; Sela, D.A.; German, J.B.; Mills, D.A. Comparative transcriptomics reveals key differences in the response to milk oligosaccharides of infant gut-associated bifidobacteria. Sci. Rep. 2015, 5, 13517. [CrossRef] [PubMed]

24. Parkar, S.G.; Rosendale, D.I.; Stoklosinski, H.M.; Jobsis, C.M.H.; Hedderley, D.I.; Gopal, P. Complementary food ingredients alter infant gut microbiome composition and metabolism in vitro. Microorganisms 2021, 9, 2089. [CrossRef] [PubMed]

25. Korpela, K.; De Vos, W.M. Early life colonization of the human gut: Microbes matter everywhere. Curr. Opin. Microbiol. 2018, 44, 70-78. [CrossRef] [PubMed]

26. Stewart, C.J.; Ajami, N.J.; O’Brien, J.L.; Hutchinson, D.S.; Smith, D.P.; Wong, M.C.; Ross, M.C.; Lloyd, R.E.; Doddapaneni, H.; Metcalf, G.A.; et al. Temporal development of the gut microbiome in early childhood from the TEDDY study. Nature 2018, 562, 583-588. [CrossRef]

27. Esparbès, P.; Legrand, A.; Bandiaky, O.N.; Chéraud-Carpentier, M.; Martin, H.; Montassier, E.; Soueidan, A. Subgingival microbiota and cytokines profile changes in patients with periodontitis: A pilot study comparing healthy and diseased sites in the same oral cavities. Microorganisms 2021, 9, 2364. [CrossRef]

28. Patini, R.; Staderini, E.; Lajolo, C.; Lopetuso, L.; Mohammed, H.; Rimondini, L.; Rocchetti, V.; Franceschi, F.; Cordaro, M.; Gallenzi, P. Relationship between oral microbiota and periodontal disease: A systematic review. Eur. Rev. Med. Pharmacol. Sci. 2018, 22, 5775-5788. [CrossRef]

29. Farup, P.G.; Maseng, M.G. Are faecal microbiota analyses on species-level suitable clinical biomarkers? A pilot study in subjects with morbid obesity. Microorganisms 2021, 9, 664. [CrossRef]

30. Duan, M.; Wang, Y.; Zhang, Q.; Zou, R.; Guo, M.; Zheng, H. Characteristics of gut microbiota in people with obesity. PLoS ONE 2021, 16, e0255446. [CrossRef]

31. Kasai, C.; Sugimoto, K.; Moritani, I.; Tanaka, J.; Oya, Y.; Inoue, H.; Tameda, M.; Shiraki, K.; Ito, M.; Takei, Y.; et al. Comparison of the gut microbiota composition between obese and non-obese individuals in a Japanese population, as analyzed by terminal restriction fragment length polymorphism and next-generation sequencing. BMC Gastroenterol. 2015, 15, 1-10. [CrossRef]

32. Million, M.; Angelakis, E.; Maraninchi, M.; Henry, M.; Giorgi, R.; Valero, R.; Vialettes, B.; Raoult, D. Correlation between body mass index and gut concentrations of Lactobacillus reuteri, Bifidobacterium animalis, Methanobrevibacter smithii and Escherichia coli. Int. J. Obes. 2013, 37, 1460-1466. [CrossRef] [PubMed]

33. Pinart, M.; Dötsch, A.; Schlicht, K.; Laudes, M.; Bouwman, J.; Forslund, S.K.; Pischon, T.; Nimptsch, K. Gut microbiome composition in obese and non-obese persons: A systematic review and meta-analysis. Nutrients 2021, 14, 12. [CrossRef] [PubMed]

34. Xu, Y.; Wang, N.; Tan, H.-Y.; Li, S.; Zhang, C.; Feng, Y. Function of Akkermansia muciniphila in obesity: Interactions with lipid metabolism, immune response and gut systems. Front. Microbiol. 2020, 11, 219. [CrossRef] [PubMed]

35. Mancilla, V.J.; Mann, A.E.; Zhang, Y.; Allen, M.S. The adult phenylketonuria (PKU) gut microbiome. Microorganisms 2021, 9 , 530. [CrossRef]

36. Parkar, S.G.; Trower, T.M.; Stevenson, D.E. Fecal microbial metabolism of polyphenols and its effects on human gut microbiota Anaerobe 2013, 23, 12-19. [CrossRef]

37. Tuohy, K.M.; Conterno, L.; Gasperotti, M.; Viola, R. Up-Regulating the human intestinal microbiome using whole plant foods, polyphenols, and/or fiber. J. Agric. Food Chem. 2012, 60, 8776-8782. [CrossRef]

38. Parkar, S.G.; Simmons, L.; Herath, T.D.; Phipps, J.E.; Trower, T.M.; Hedderley, D.I.; McGhie, T.K.; Blatchford, P.; Ansell, J.; Sutton, K.H.; et al. Evaluation of the prebiotic potential of five kiwifruit cultivars after simulated gastrointestinal digestion and fermentation with human faecal bacteria. Int. J. Food Sci. Tech. 2018, 53, 1203-1210. [CrossRef]

39. Parkar, S.G.; Jobsis, C.M.H.; Trower, T.M.; Cooney, J.M.; Hedderley, D.I.; Bentley-Hewitt, K.L. Bioaminergic responses in an in vitro system studying human gut microbiota-kiwifruit interactions. Microorganisms 2020, 8, 1582. [CrossRef]

40. Strandwitz, P. Neurotransmitter modulation by the gut microbiota. Brain Res. 2018, 1693, 128-133. [CrossRef]

41. Lin, H.-H.; Tsai, P.-S.; Fang, S.-C.; Liu, J.-F. Effect of kiwifruit consumption on sleep quality in adults with sleep problems. Asia Pac. J. Clin. Nutr. 2011, 20, 169-174.

42. Yang, H.; Lee, Y.-C.; Han, K.-S.; Singh, H.; Yoon, M.; Park, J.-H.; Cho, C.-W.; Cho, S. Green and gold kiwifruit peel ethanol extracts potentiate pentobarbital-induced sleep in mice via a GABAergic mechanism. Food Chem. 2013, 136, 160-163. [CrossRef] [PubMed]

43. Vamanu, E.; Dinu, L.D.; Pelinescu, D.R.; Gatea, F. Therapeutic properties of edible mushrooms and herbal teas in gut microbiota modulation. Microorganisms 2021, 9, 1262. [CrossRef] [PubMed]

44. Reed, A.D.; Theriot, C.M. Contribution of inhibitory metabolites and competition for nutrients to colonization resistance against Clostridioides difficile by commensal Clostridium. Microorganisms 2021, 9, 371. [CrossRef] [PubMed] 